\title{
FDI - Employment Short-Run Dynamics in South Africa: VECM Approach
}

\author{
John Khumalo \\ Department of Economics, UNISA, South Africa \\ P.O. Box 392, UNISA 0003, South Africa \\ Email:khumamj@unisa.ac.za
}

Odirile Mosıane

Email: mosianeodirile@yahoo.com

\section{Doi:10.5901/mjss.2014.v5n20p522}

Abstract

This study uses the annual time -series data covering the period 1970 to 2013 to analyses the effect of employment on foreign direct investment (FDI) in South Africa using the vector error correction modelling (VECM). For this purpose, the behavioural patterns and quality of data are tested and these include the unit root test using the ZAU test and as well as the Correlograms for serial correlations. The ZA unit test results show that FDI, employment, real interest rates and real effective exchange rate are integrated of order zero while inflation was found to contain unit root. The Johansen cointegration test was performed to establish the number of cointegration vectors in the model and the test provides evidence of at most one cointegrating vector. With the long-run relationship present, the possibility of having short-run shocks was done with the aid of the VECM. VECM indicates that employment affects FDI positively in the short-run. Therefore, stable and economically sound environment and sound macroeconomic fundamentals are required in order to improve attract more FDI into South Africa.

Keywords: FDI, Employment, VECM, ZAU test, Cointegration

\section{Introduction}

While foreign direct investment (FDI) is fundamental in an economy, it should be noted that a large proportion of FDI in South Africa takes the form of mergers and acquisitions instead of greenfields entry. Taking over an existing business may not necessarily translate into more employment at least until the foreign investor sees an opportunity for growth. The attitude towards inwards Foreign Direct Investments has changed considerably over the last couple of decades, as most countries having relaxed their policies to attract investments from multinational corporations (Blomstrom and Kokko, 2003). The relaxed policies include granting investors easier entry, ability to borrow locally, relaxation of land and mining concession ownership. The foreign direct investments is associated with some positive effects such as adoption of foreign technology and know- how, which can happen in different ways like licensing agreements, employee training and the introduction of new processes and the linkages between foreign and domestic firms (Alfaro et al, 2006). It can be argued that the dynamics of FDI can be determined by the response of some fundamental macroeconomic variables such as employment, Inflation, real exchange rates and interest rates.

Unemployment in South Africa (SA) is heavily concentrated among young unskilled and black population.SA has been and it is still having a poor record on unemployment and this poor record on employment represents not only economic tragedy, it poses a significant threat to the stability and eventual health of SA democracy (Rodrick 2006) 
Figure 1. FDI and Employment in South Africa

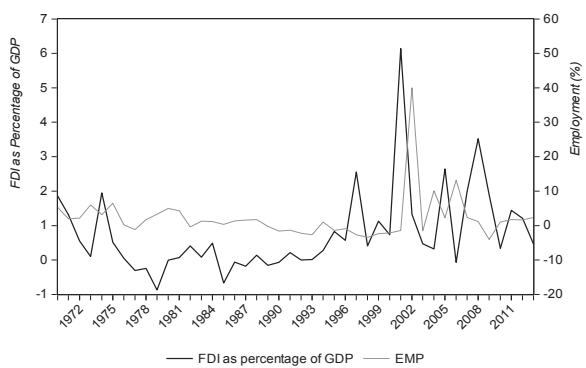

Figure 1 above presents the historical patterns of both FDI and employment for the period under consideration. Employment has been growing steadily until the year 2002 where the country realised high employment. This was also followed by increases in FDI, but in 2003, a drop was observed.

\section{Empirical Literature}

Mwilima (2003), suggests that the mechanism that is used for inward and the type of FDI that is received by a country will have a varying impact on job creation for domestic economy. The study laid a specific emphasis on Africa as a whole and he takes an example of an inward FDI that comes in the form of a cross border merger and acquisition which is likely to have a less impact on the local labour market as compared to Greenfield investments where firms seek new labour markets to function. In his context, he suggest that the international experiences have shown that is hardly accompanied by a substantial employment creation and in some cases it might even lead to job losses in a case where public companies are privatised. Thomo (2010) in his investigation of FDI on skills development and job creation in SA concluded that an inward FDI impacts positively on job creation when in the form of Greenfield investments. His study used questionnaires designed to collect both quantitative and qualitative data through closed and open ended questions.

Mpanju (2012) uses the OLS method to analyse the data collected from 1990 to 2008 of FDI and economic growth, and from the results obtained the conclusion was made that Tanzania's employment does not depend upon . The data that was collected on the study, it is evident that most jobs came from the economic infrastructure, manufacturing sector \&agricultural sector of which these are the sectors that mostly require low-medium skilled participants.

Rizvi et al (2009) used a panel data analysis on the impact of FDI on employment opportunities with empirical evidence from Pakistan, India and china, and the data used was for the period of 24 years (1985 - 2008). The long run relationship for the variables was conducted by firstly checking the order of integration by applying the unit root tests given by IM - Pesaran- Shin (IPS) and the Pedrons test of cointegration. The last stage was to apply a Seemingly Unrelated regression (SUR) test to find out whether has an Impact on employment opportunities on the three countries. The results showed that FDI does not have any impact on the creation of employment on the above mentioned three countries. Macuk et al (2013) used somewhat a similar approach of data testing from a panel of data of seven developing nations. On the panel unit root test, they performed the LLC and the IPS tests and for panel cointegration tests they performed Pedroni's ${ }^{1}$ tests in determining the long run relationship between and Unemployment. The findings indicated that there was a long run relationship between variables and that increases unemployment in turkey and Argentina and reduces unemployment in Thailand. The analysis argued that these negative effects of on unemployment is mainly the end results of brownfield investments which is composed of mergers and acquisitions

\section{Method of Analysis}

The interrelationship between FDI and employment is established using the vector error correction (VECM) model bestowed within the vector autoregression (VAR) developed by Johansen (1988) and Johansen (1991). The general dynamic form of the econometric model used in this study is:

$$
\mathbf{F D I}_{\mathrm{t}}=\boldsymbol{\Omega}_{0}+\sum_{\mathrm{i}=1}^{k} \boldsymbol{\Omega}_{\mathrm{ii}} \mathrm{FDI}_{\mathrm{t}-\mathrm{i}}+\sum_{\mathrm{i}=0}^{k} \boldsymbol{\Omega}_{\mathrm{ti}} \mathbf{X}_{\mathrm{t}-\mathrm{i}}+\boldsymbol{\delta}_{\mathbf{0}} \boldsymbol{\Phi}_{\mathrm{t}}+\pi_{\mathrm{t}}
$$

\footnotetext{
${ }^{1}$ See Pedroni (1999)
} 
Where, $F \mathrm{Fl}_{\mathrm{t}}=$ foreign direct investment, $\mathrm{X}_{\mathrm{t}-\mathrm{i}}=$ represents the set of all explanatory variables to be included in the model and their lags, including the main explanatory variable (employment). $D_{t}$ represents a set of deterministic terms (dummies, trends and others). $\pi_{t}$ is a well behaved error term. Consequently, specifying equation (1) as a VAR system of equations gives equation (2), which is compactly written as equation (3):

$$
\begin{aligned}
& \mathbf{X}_{\mathrm{t}}=\boldsymbol{\delta}_{0} \boldsymbol{\Phi}_{\mathrm{t}}+\boldsymbol{\delta}_{1} \mathbf{X}_{\mathrm{t}-1}+\boldsymbol{\delta}_{2} \mathbf{X}_{\mathrm{t}-2}+\ldots \ldots \ldots \ldots \ldots+\boldsymbol{\delta}_{\mathrm{k}} \mathbf{X}_{\mathrm{t}-\mathrm{k}}+\boldsymbol{\varepsilon}_{\mathrm{t}} \\
& \mathbf{X}_{\mathrm{t}}=\boldsymbol{\delta}_{0} \boldsymbol{\Phi}_{\mathrm{t}}+\sum_{\mathrm{i}=1}^{\mathrm{k}} \boldsymbol{\delta}_{\mathrm{i}} \mathbf{X}_{\mathrm{t}-\mathrm{i}}+\boldsymbol{\varepsilon}_{\mathrm{t}}
\end{aligned}
$$

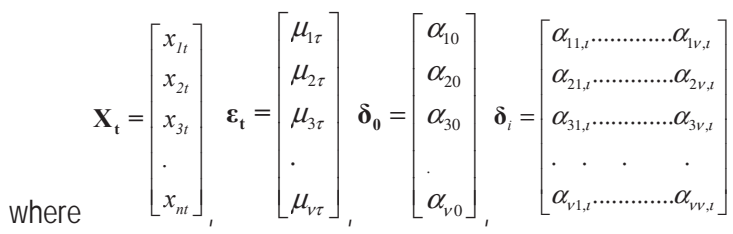

$\sum_{i=1}^{k} \delta_{i} \mathbf{X}_{t-1}$ is the summation of vector of lagged endogenous variables in the system. $X_{t}$ is a nx1column vector of all variables that enter system, $\boldsymbol{\Phi}_{t}=$ Vector holding deterministic terms (intercepts, trends, dummies), $\boldsymbol{\varepsilon}_{t}=\mathrm{n \times 1}$ dimensional vector of multivariate random errors with mean zero and covariance matrix, thus error terms are assumed contemporaneously correlated but not autocorrelated, ${ }_{i}=$ matrices of coefficients to estimated. Therefore, in order to capture the short-run dynamics of variables in the system, equation (2) is parameterized to give the VECM specification, given in equation (5) below.

$$
\Delta X_{t}=\beta \Phi_{t}+\sum_{i=1}^{k-1} \Psi_{i} \Delta X_{t-1}+\Gamma X_{t-1}+\Psi_{k-1} X_{t-k+1}+\pi_{t}
$$

Where matrix $\boldsymbol{\Gamma}=\boldsymbol{\alpha} \cdot \boldsymbol{\beta}^{\prime}$ (thus $\boldsymbol{\Gamma}$ is disintegrated into two matrices of dimensions [n $\mathrm{r} r$ ], and $r$ is the number of cointegrating vectors), $\alpha$ is a matrix of adjustment coefficients or the loading matrix and contains the short run dynamics while $\beta$ is the matrix containing the long run equilibrium relationships or long run coefficients.

\subsection{Unit root tests}

Testing for the stationarity of economic time series is crucial since standard econometric methodologies assume stationarity in the time series while they are, in fact, non-stationary and thus leading to inappropriate statistical tests and erroneous and misleading inferences. In empirical research, regressing of one non-stationary series on the other may lead to spurious regression, which adversely affects the legitimacy of the standard statistical tests. Various solutions are proposed to deal with non-stationary time series; these include differencing of the series to reach stationarity. The most notable tests include the ADF proposed by Dickey \& Fuller (1979) as well as the PP by Phillips \& Perron (1988), but these tests do not take into account the structural breaks in the series. It is expected that during the sample period selected for the study, major economic happenings would have been occurred which could have generated potential nonstationarity in the series. Such non-stationarity could have potential implications for under or over estimation of the results. In order to overcome such issues, the Zivot - Andrews (ZAU) ${ }^{2}$ structural break test has been conducted. Table 1 below shows the results of the unit root tests applied in this study.

Table 1: ZAU Unit Root Test and ADF Unit Root Test Results

ZAU Test

\begin{tabular}{ccc|cc}
\multicolumn{2}{c}{ ZAU Test } & ADF Test \\
\hline Variables & ZA Statistic & 5\% Critical value & ADF Statistic & 5\% Critical value \\
\hline$F D I_{t}$ & $-6.9099^{\star *}$ & -4.93 & -1.09211 & -2.9458 \\
$E M P_{t}$ & $-9.1740^{\star \star}$ & -4.93 & $-6.7154^{\star \star}$ & -2.914 \\
$R E E R_{t}$ & $-6.3619^{\star \star}$ & -4.93 & $-5.6448^{* \star}$ & -2.9314 \\
$R I R_{t}$ & $-5.1219^{\star \star}$ & -5.08 & $-3.5499^{\star *}$ & -3.5180 \\
$I N F_{t}$ & -2.3316 & -5.82 & -2.3972 & -3.5484 \\
\hline
\end{tabular}


The lag length for the series was determined by Schwarz information criterion (SBC). All variables include an intercept and INFt includes an intercept and trend. The ZA unit root test results in table 1 above indicate that all variables; $F D I_{t}, E M P_{t}$ , ${ }^{R E E R_{t}}$ and ${ }^{R I R_{t}}$ are integrated of order zero $(I(0))$ whereas ${ }^{I N F_{t}}$ is I(1). The ADF test on the other hand shows that ${ }^{F D I_{t}}$ and ${ }^{I N F}$ are I(1).

\subsection{Cointegration (Long-Run Relationship)}

The cointegration results are presented in table 2 and table below. The trace test rejects null hypothesis of zero cointegrating vector at 5 percent level of significance in favour of at most one cointegrating vector. The critical trace statistic at 5 percent level of significance is 98.373 . Therefore, the computed trace statistic of 98.373 is greater than the critical vale at 5 percent level of significance $(98.373>69.818)$.

Table 2: Cointegration analysis, and testing for Cointegration Rank (r) Results

\begin{tabular}{ccccc}
\hline $\mathrm{H}_{0}$ & Eigenvalue & Trace Statistic & 5\% Critical Value & Prob. $^{\text {** }}$ \\
\hline $\mathrm{H}_{0}: \mathrm{r}=0^{*}$ & 0.711552 & 98.37377 & 69.81889 & 0.0001 \\
$\mathrm{r} \leq 1$ & 0.414304 & 46.15760 & 47.85613 & 0.0716 \\
$\mathrm{r} \leq 2$ & 0.317829 & 23.68951 & 29.79707 & 0.2139 \\
$\mathrm{r} \leq 3$ & 0.140582 & 7.625581 & 15.49471 & 0.5063 \\
$\mathrm{r} \leq 4$ & 0.029614 & 1.262576 & 3.841466 & 0.2612 \\
\hline
\end{tabular}

Having established existence of cointegration, there was a need to pin down the exact number of cointegrating vectors, the Maximum Eigenvalue test was performed and this lead to the rejection of the null for one cointegrating vector at 5 percent level of significance and pins down that there is one cointegrating vector. The rejection of the null hypothesis is expounded by the fact that the computed maximum eigenvalue statistic at 5 percent level of significance for null hypothesis of one cointegrating vector is 52.216 and is greater than the critical the 5 percent critical value of 33.876 . This therefore indicates the rejection of the null hypothesis in favour of an alternative hypothesis of one cointegrating vector or rank 1 of the $\Pi$ matrix. See table 3 below.

Table 3: Cointegrations Analysis - Results from Max. E-value test

\begin{tabular}{ccccc}
\hline Null & Eigenvalue & Max-Eigen Stat & $5 \%$ Critical Value & Prob. $^{\text {** }}$ \\
\hline $\mathrm{H}_{0}: \mathrm{r}=0$ & 0.711552 & 52.21616 & 33.87687 & 0.0001 \\
$r=1$ & 0.414304 & 22.46810 & 27.58434 & 0.1973 \\
$r=2$ & 0.317829 & 16.06393 & 21.13162 & 0.2211 \\
$r=3$ & 0.140582 & 6.363004 & 14.26460 & 0.5671 \\
$r=4$ & 0.029614 & 1.262576 & 3.841466 & 0.2612 \\
\hline
\end{tabular}

Therefore, from the above-determined rank of the $\Pi$ matrix, the respective unrestricted normalized estimates for the two cointegrating vectors ${ }^{\beta}$, also known as the long-run elasticities and their respective unrestricted long-run adjustment coefficients are reported in tables 4 and 5 respectively. According to Charemza and Deadman (1993), the adjustment coefficients in the $\alpha$ matrix are supposed to be negative in order to be in alignment with the hypothesis of an error correction mechanism given by deviations from the long-run equilibrium or variable path, and that both ${ }^{\prime}$ and $\alpha$ coefficients attain some economic meaning after standardizing. The elements of the ${ }^{\beta}$ matrix are economically interpreted as the long-run parameters and those of the $\alpha$ matrix are referred to as the measure of the speed of adjustment of particular variables with respect to a disturbance in the equilibrium relation.

Table 4: The normalized Unrestricted Cointegrating Vectors ( The $\beta^{\prime}$ matrix)

\begin{tabular}{|c|c|c|c|c|c|}
\hline & & EMP & INF & REER & RIR \\
\hline \multirow[t]{2}{*}{$\beta_{1}^{\prime}$} & 1.000000 & -0.048214 & 0.250358 & 0.138399 & 0.080393 \\
\hline & & $(0.03505)$ & $(0.03732)$ & $(0.02652)$ & $(0.03597)$ \\
\hline
\end{tabular}


Table 5: The Unrestricted Long-run Adjustment co-efficients matrix (the $\alpha$ matrix)

\begin{tabular}{lcc}
\hline & Variable & $\alpha_{1}$ \\
\hline $\mathrm{D}(\mathrm{FDI})$ & $-0.507469(0.1713)$ \\
D(EMP) & $-0.038423(0.8099)$ \\
D(INF) & $-1.452075(0.1982)$ \\
D(REER) & $-2.633906(1.2654)$ \\
D(RIR) & $0.848342(0.5448)$ \\
\hline
\end{tabular}

Note: Values in parenthesis are the conversional $t$-values given by $t=\beta / \mathrm{se}(\beta)$ and $t=\alpha / \mathrm{se}(\alpha)$ respectively. In order to identify the unique Eigenvector, the trend in the first standardized $\beta^{1}$ Eigenvector was restricted to zero and the first variable in the first restricted to one

It was noted that the variables are cointegrated with rank order 1, which implied that there was one long-run relationships among the variables or one cointegrating vector, and such relationship was thereafter discussed, particularly that with respect. However, in order to tie the short-run dynamics of variables to their long-run values in the equation, the VECM was estimated, the results of which are presented in Table 6 . The cointegrating vector $\beta^{\prime}$ was used to blend the VECM equation 2:

$$
C V I=F D I-0.048214^{\star} E M P+0.250358^{\star} I N F+0.138399^{\star} R E E R+0.080393^{*} R I R
$$

Table 6: Results for the Short-run Foreign Direct Investment

\begin{tabular}{|c|c|c|c|}
\hline Regressor & Co-efficient & Standard Error & T-Ratio \\
\hline Constant & -0.034075 & -0.19268 & 0.17685 \\
\hline$\Delta \mathrm{FDI}(-1)$ & 0.163668 & 0.31081 & -0.52658 \\
\hline$\Delta \mathrm{FDI}(-2)$ & 0.014801 & 0.24817 & 0.05964 \\
\hline$\Delta \operatorname{EMP}(-1)$ & -0.037357 & 0.04380 & -0.85289 \\
\hline$\Delta \operatorname{EMP}(-2)$ & -0.050889 & 0.03179 & -1.60092 \\
\hline$\Delta \mathrm{INF}(-1)$ & 0.097972 & 0.10661 & 0.91661 \\
\hline$\Delta \mathrm{INF}(-2)$ & 0.019652 & 0.11584 & 0.16964 \\
\hline$\Delta$ REER $(-1)$ & 0.042689 & 0.04125 & 1.03488 \\
\hline$\Delta$ REER $(-2)$ & 0.039580 & 0.03562 & 1.11109 \\
\hline$\Delta \mathrm{RIR}(-1)$ & 0.016120 & 0.06994 & 0.23048 \\
\hline$\Delta \mathrm{RIR}(-2)$ & 0.000917 & 0.05902 & 0.01553 \\
\hline CVI (-1) & -0.803683 & 0.33512 & -2.39816 \\
\hline$R^{2}=0.56, F=3.3429$ & & & \\
\hline
\end{tabular}

From the results depicted in Table 6 above, the value of $\mathrm{R}^{2}(0.56)$ shows that about 56 percent of the variations in FDI in the short-run are explained by the set of explanatory variables included in the model. The VECM results reveal that about 1 percent of the disequilibrium is corrected each year by changes in FDI in South Africa. This is justified by the coefficient -0.803683 . This coefficient bears the expected sign (negative) as per theory. The error correction suggests the validity of the equilibrium relationship indicating the existence of market forces that operate to restore long - run equilibrium after a short - run shock.

\subsection{Other diagnostic tests}

The validity of the test results does not only depend on the presented tests but also on the normality, serial correlation LM as well as heteroskedasticity tests. The serial correlation tests results are presented in table 6 below and the results that there is no evidence of serial correlation amongst the residuals as shown by the probability values. The null hypothesis of no serial correlation is accepted at 5 percent level of significance. 
Table 6 : VEC Residual Serial Correlation LM Test Results

Null Hypothesis: no serial correlation at lag order $\mathrm{h}$

\begin{tabular}{ccc}
\hline Lags & LM-Stat & Prob \\
\hline 1 & 24.39526 & 0.4966 \\
2 & 12.53978 & 0.9817 \\
3 & 16.23579 & 0.9076 \\
4 & 28.48526 & 0.2860 \\
5 & 41.42984 & 0.0207 \\
6 & 31.78848 & 0.1642 \\
7 & 23.09256 & 0.5722 \\
8 & 27.11492 & 0.3502 \\
9 & 20.31440 & 0.7301 \\
10 & 24.61277 & 0.4842 \\
11 & 20.66789 & 0.7110 \\
12 & 22.57233 & 0.6025 \\
\hline
\end{tabular}

The normality test also showed that the residual are multivariate normal.

Table 7: VEC Residual Normality Test results

Orthogonalization: Residual Correlation (Doornik-Hansen)

Null Hypothesis: residuals are multivariate normal

\begin{tabular}{ccccc}
\hline Component & Skewness & Chi-sq & df & Prob. \\
\hline 1 & 1.550485 & 13.43407 & 1 & 0.0002 \\
2 & 0.305675 & 0.799099 & 1 & 0.3714 \\
3 & -0.087839 & 0.067708 & 1 & 0.7947 \\
4 & -0.008301 & 0.000606 & 1 & 0.9804 \\
5 & 0.509829 & 2.122483 & 1 & 0.1452 \\
\hline Joint & & 16.42396 & 5 & 0.0057 \\
\hline Component & Kurtosis & Chi-sq & df & Prob. \\
\hline 1 & 7.954861 & 0.982834 & 1 & 0.3215 \\
2 & 5.256533 & 12.92793 & 1 & 0.0003 \\
4 & 2.751593 & 0.116546 & 1 & 0.7328 \\
5 & 3.118694 & 1.059326 & 1 & 0.3034 \\
Joint & 4.773436 & 6.715958 & 1 & 0.0096 \\
\hline
\end{tabular}

lastly the heteroskedasticity tests was performed to determine if there is any evidence of heteroskedasticity in the model and the results ${ }^{3}$ show that there is no heteroskedasticity in the model.

\section{Conclusion}

The study utilised the time series annual data covering the period 1970 and 2013 for South Africa. Having performed the unit root tests as a precautionary measure using the ZAU test and found that only inflation was integrated of order one, we use the VEC approach to detect he short-run relationship between FDI and employment in South Africa. The generalto-specific approach was also utilised estimate the error correction model(ECM) whereby we start with a maximum lag order of 8 and in each stage drop out all insignificant stationary regressors until the best specification is obtained. The estimation results of VEC model FDI model are presented in table 6 . These results suggest that the VECM is correctly specified since all the diagnostic tests are satisfactory. For instance, the null hypothesis of no serial correlation and heteroskedasticity in the FDI model is not rejected at 5 percent level of significance. In the same way, the normality test showed that the functional form of the VECM is correct.

The results show that there is a positive long-run relation between FDI and employment in South Africa. This means that a one percent increase in employment would increase FDI by about 5 percent. Increases in employment

\footnotetext{
${ }^{3}$ For more detailed result contact author
} 
imply a decline or fall in unemployment and this brings positive investor confidence. Inflation, real effective exchange rate as well as real interest rate however yield negative relationship. The negative coefficient of the inflation suggests that high inflationary pressures would scare away the foreign investors. When the South African Rand (R) appreciates, it becomes expensive for foreign investors to buy the local currency. This limits the inwards FDI and hence investors seek other alternative investment opportunities elsewhere. Finally, when interest rates are high, borrowing becomes quite expensive for investors so they make less real investment. This is shown by the negative coefficient of about 8 percent.

\section{References}

Alfaro L. et al. (2006). How does promotes growth? Exploring the effects of financial markets on linkages. Working paper No 07-013. USA, Harvard Business School

Blomstrom M and Koko A, (2003). The economy of Foreign Direct Investments incentives. Working paper No 168. Sweden. Stockholm School of Economics.

Blomstrom, M,. (2006). Study on FDI and regional development. Final report, Copenhagen economics. http:/lec.europa.eu Iregional policy/sources/docgener/studies/pdf/fdi2006. pdf. Accessed 16 April 2014.

Charemza, W.W. \& Deadman, D.F. (1992), New Directions in Econometric Practice. Edward Elgar, England.

Dickey, D.A. \& Fuller, W.A. (1979). Distribution of estimators for Autoregressive Time series with a unit root. Journal of American Statistical Association, 4(366), pp. 427-431.

Johansen, S. (1988). Statistical Analysis of Cointegration Vectors. Journal of Economic Dynamics and Control, 12(4), pp. 231-254.

Johansen, S. (1991). Estimation and Hypothesis Testing of Cointegration Vectors in Gaussian Vector Autoregressive Models. Econometrica, 59(6), pp. 1551-15580

Phillips, P.C. \& Perron, P. (1988). Testing for a unit root in time series regression. Biometrika, 75(2), pp. 335-346.

Mpanju A.K. (2012). The impact of Foreign Direct Investment on employment in Tanzania. Zenith International Journal of Business Economics \& Management Research, 2(1), pp. 126-139.

Mwilima, N.. (2003). Foreign Direct Investment in Africa. Social Observatory Pilot Project, Labour Resource and research Institute.

Pedroni, P. (1999). Critical values for cointegration tests in heterogeneous panels with multiple regressors. Oxford Bulletin of economics and statistics, 61, pp. 653-670.

Rizvi A.Z. \& Nishat M.. (2009). The impact of Foreign Direct Investment opportunities: Panel data analysis: Empirical evidence from Pakistan, India and China. The Pakistan Development Review, 48(4), pp. 841-851.

Thomo S, (2010). An investigation of the impact of inward Foreign Direct Investment on skills Development \& Job creation in South Africa. Masters dissertation, University of Pretoria, South Africa.

Zivot, E., \& Andrews, D.W., (1992). Further evidence on the great crash, the oil price shock and the unit root hypothesis. Journal of Business and Economic Statistics, 10(3), pp. 251-270. 